\title{
Precipitation-Climate Sensitivity to Initial Conditions in an Atmospheric General Circulation Model
}

\author{
C. Covey
}

M.F. Wehner

March 1997

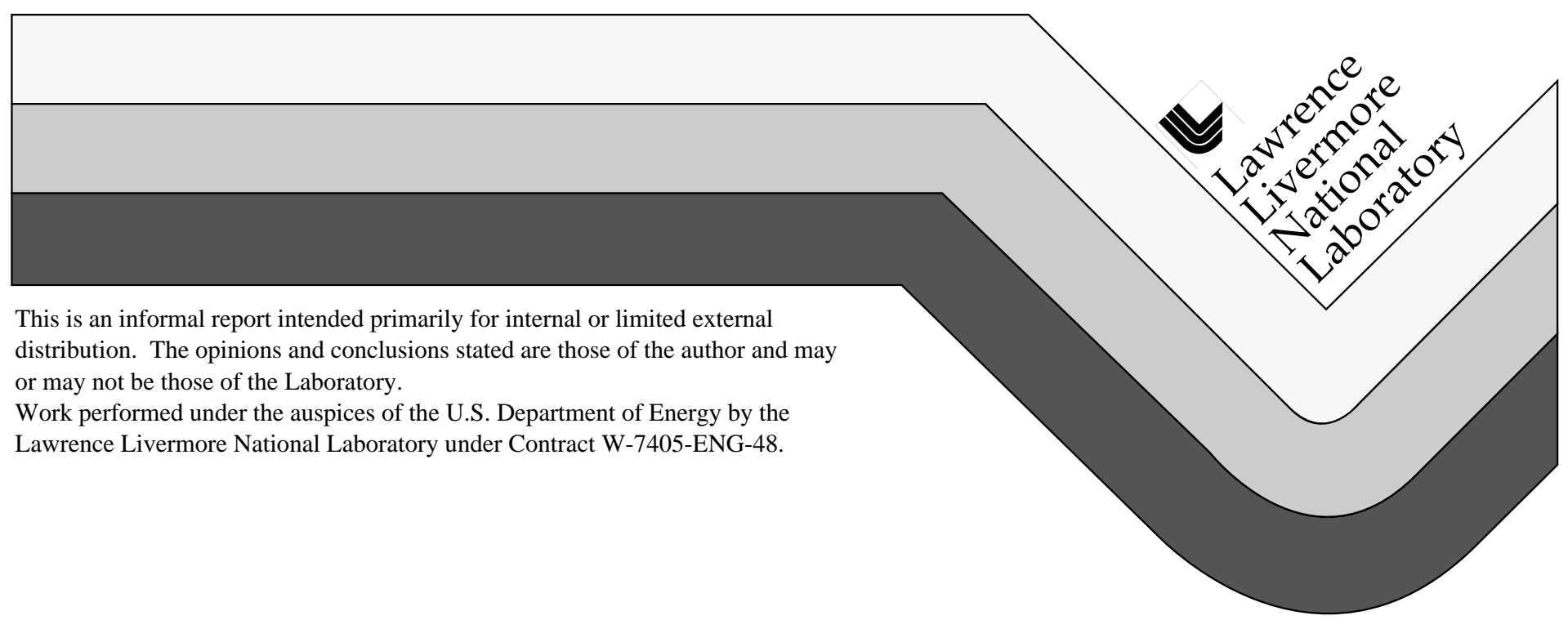




\section{DISCLAIMER}

This document was prepared as an account of work sponsored by an agency of the United States Government. Neither the United States Government nor the University of California nor any of their employees, makes any warranty, express or implied, or assumes any legal liability or responsibility for the accuracy, completeness, or usefulness of any information, apparatus, product, or process disclosed, or represents that its use would not infringe privately owned rights. Reference herein to any specific commercial product, process, or service by trade name, trademark, manufacturer, or otherwise, does not necessarily constitute or imply its endorsement, recommendation, or favoring by the United States Government or the University of California. The views and opinions of authors expressed herein do not necessarily state or reflect those of the United States Government or the University of California, and shall not be used for advertising or product endorsement purposes.

This report has been reproduced directly from the best available copy.

Available to DOE and DOE contractors from the Office of Scientific and Technical Information P.O. Box 62, Oak Ridge, TN 37831

Prices available from (423) 576-8401

Available to the public from the National Technical Information Service

U.S. Department of Commerce 5285 Port Royal Rd. Springfield, VA 22161 
Precipitation-Climate Sensitivity to Initial Conditions in an Atmospheric General Circulation Model

\author{
Curt Covey \\ Michael F. Wehner \\ Atmospheric Science Division \\ Lawrence Livermore National Laboratory \\ Mail Code L-264 \\ Livermore, CA 94551
}

for submission to Geophysical Research Letters

March 1997 


\begin{abstract}
Atmospheric climate, in contrast to weather, is traditionally considered to be determined by boundary conditions such as sea surface temperature (SST). To test this hypothesis, we examined annual mean precipitation from an ensemble of 20 general circulation model (GCM) simulations. Ensemble members were forced with identical 10-year series of SST and sea ice, but they began with slightly differing initial conditions. A surprisingly small proportion of the variance in the output is attributable to the effects of boundary forcing. This result-and similar evidence from smaller ensembles of other GCM simulations-implies that long-term precipitation variations are mostly unpredictable, even if SST forecasts are "perfect."
\end{abstract}




\section{Introduction}

It has long been recognized that sensitivity to initial conditions limits weather forecasts to at most a few weeks' time horizon (see, e.g., Lorenz, 1993). One might suppose that in contrast to an atmospheric GCM's detailed weather simulation, its long-term statistics (or climate) over a period of years would have little memory of initial conditions. The supposition that boundary conditions rather than atmospheric initial conditions are important on such time scales underlies extensive efforts to predict future climate from present sea surface conditions. These efforts have succeeded most notably in forecasting El Niño events (Barnett et al., 1988). Such work, however, does not rule out the existence of limits on climate predictability due to uncertain initial conditions.

We used a new atmospheric GCM (Wehner and Covey, 1995) to address this issue. Our model's efficient execution on parallel-processing computers enabled us to run a large number of 10 -year simulations with differing initial conditions, but identical prescribed SST and sea ice boundary conditions. The boundary conditions vary from year to year (as observed), providing a measure of SST and sea ice forcing of climate variations. In what follows, we assess this boundary-forced variance relative to total output variance, and we compare our results with previous studies that used different models and less extensive ensembles. Our study is concerned with the effects of atmospheric initial conditions. Analogous sensitivity to initial conditions in the ocean portion of a 
coupled ocean-atmosphere model can also limit climate predictability (Cubasch et al., 1994).

In this report we focus on just one meteorological variable: precipitation. This variable is perhaps the most relevant to human activities and natural ecosystems, and it certainly is among the most difficult for models to predict.

\section{Experimental Design}

Our model is a version of the UCLA GCM (Suarez et al., 1983) recoded for efficient execution on massively parallel computers. We ran the model at $4^{\circ}$ by $5^{\circ}$ latitude-longitude resolution with 15 vertical levels. A general discussion of both the model's computational performance and its simulated climatology is provided by Wehner and Covey (1995).

For the model's boundary conditions, we used observed monthly mean 1979-1988 SST and sea ice from the Atmospheric Model Intercomparison Project (AMIP; see Gates et al., 1997). To provide differing initial conditions, we ran our model for 20 simulated days in January 1979 . Then we selected the 20 model states obtained at noon, Greenwich mean time, on each day. These states served as initial conditions for an ensemble of 10-year runs, each of which began on January 1, 1979.

We analyzed the resulting 200 annual mean precipitation fields following Rowell et al. (1995). In this method, sensitivity to initial conditions (internal 
variability, $\sigma_{\mathbb{N}}^{2}$ ) is determined by the variance of ensemble members about the ensemble mean. This variance is first calculated for each year and then averaged over years. Variability due to SST and sea ice forcing (externally forced variability, $\sigma_{\mathrm{SST}}^{2}$ ) is obtained analogously: by first averaging over the ensemble for each year, then taking the interannual variance of the ensemble means, and finally correcting to form an unbiased estimator. The ratios $\sigma_{\mathrm{INT}}^{2} /\left(\sigma_{\mathrm{INT}}^{2}+\sigma_{\mathrm{SST}}^{2}\right)$ and $\sigma_{\mathrm{SST}}^{2} /\left(\sigma_{\mathrm{INT}}^{2}+\sigma_{\mathrm{SST}}^{2}\right)$ give the fractions of output variance due to differing initial conditions and changing boundary conditions, respectively.

Zwiers (1997) advocates a somewhat different analysis of ensemble variance. When we applied Zwiers' method to our model output, we obtained a fraction of variance due to changing boundary conditions that is practically identical to the result shown below.

\section{Results}

To take model-simulated results seriously, one must first check that they match reasonably with observations. Figure 1 compares the average of our model's annual mean precipitation—taken over all years and all ensemble members-with estimates of the real-world climatology. We show two such estimates to provide a feeling for observational uncertainties. The estimate of Legates and Willmott (1990) has been the standard for several years. The new estimate of Xi and Arkin (1996) incorporates reanalysis of surface observations 
and satellite data. It is apparent that the difference between the model simulation and either set of observations is roughly the same magnitude as the difference between the two sets of observations. Note, however, that the model simulates too much precipitation in general. Our global mean, $3.6 \mathrm{~mm}$ per day, is 33\% greater than $\mathrm{X}$ and Arking's estimate. The model's precipitation lies near the upper limit of simulations by 30 AMIP models, although it does not appear as an obvious "outlier" when zonal mean precipitation from the AMIP models is shown (Gates et al., 1997).

Turning to the interannual variance (Figure 2), we obtain about the same magnitude and spatial pattern as Xi and Arking's observations. (Legates and . Wilmott's data set does not provide this quantity.) The model, however, tends to overestimate variance over oceans and underestimate it over land. Finally, to examine the correlation structure of this variance, we show in Figure 3 the difference between 1983 and 1988 precipitation. We chose these two years because they represent extreme phases of the El Niño / Southern Oscillation (ENSO) "cycle." Once again, the model shows a correspondence with observations that we deem adequate for our study.

Accordingly, in Figure 4 we show the fraction of model variance due to changing SST and sea ice boundary conditions. We have deliberated plotted our result without smoothing across model grid points. To assess statistical significance, we recalculated using only half (every other member) of the ensemble and obtained virtually the same result, as shown. The only extensive 
contiguous areas in which the fraction exceeds 0.5 lie in the tropical and subtropical Pacific Ocean, and in sea ice margins. Elsewhere this fraction is generally $<0.3$. Equivalently, the fraction of variance due to differing initial conditions is generally $>0.7$ (globally averaged, it is 0.85 ).

\section{Conclusions}

Our result suggests that seasonal to interannual variations in precipitation are mostly not predictable, even if SST and sea ice are known perfectly. We hasten to add that predictability at certain seasons and locations is not only achievable but also of the utmost importance to human affairs (e.g., Barnett et al., 1988). Figure 4 shows that well over half the precipitation variance in the eastern tropical Pacific arises from SST (presumably sea ice makes a minor contribution in this region). Repeating the analysis for a particular season of the year, rather than the annual mean, and perhaps focusing on particular years such as 1983 and 1988 , would provide a more optimistic view of predictability. But in this work we are concerned with a global assessment of the fraction of precipitation variance that may be attributed to changing boundary conditions on the atmosphere. That fraction is surprisingly small in our model.

This general sense of unpredictability is consistent with results from other GCMs. From an analysis of seasonal (March-April-May) precipitation variance, Rowell (1996) also obtains a fraction due to boundary conditions that is generally 
small outside the tropics. (However, Rowell's model indicates greater predictability than ours for annual mean precipitation in some regions, such as the equatorial Atlantic and parts of South America [D. P. Rowell, personal communication].) Zwiers (1997) does not examine precipitation, but his variance of 500-hPa height shows little predictability outside the Tropics, and his fraction due to boundary conditions for this quantity is quite similar to ours. It seems possible that humanity's future ability to predict climate change will encounter a fundamental limit.

Acknowledgements. This work was performed under auspices of the U.S. Department of Energy's Environmental Sciences Division by the Lawrence Livermore National Laboratory under Contract No. W-7405-ENG-48. We thank T. P. Barnett and D. P. Rowell for comments on the manuscript.

\section{References}

T. N. Barnett, N. Graham, M. Cane, S. Zebiak, S. Dolan, J. O'Brien and D. Legler, “On the Prediction of the El Niño of 1986-1987," Science 241, 192-196 (1988)

U. Cubasch, B. D. Santer, A. Hellbach, G. Hegerl, H. Hock, E. Maier-Reimer, U. Mikolajewicz, A. Stossel and R. Voss, "Monte Carlo Climate Change Forecasts with a Global Coupled Ocean-Atmosphere Model," Climate Dynamics 10, 1-19 (1994) 
W. L. Gates and 16 co-authors, "Preliminary Results from the Atmospheric Model Intercomparison Project," in preparation for the Bulletin of the American Meteorological Society (1997)

D. R. Legates and C. J. Willmott, "Mean Seasonal and Spatial Variability in Guage Corrected, Global Precipitation," International Journal of Climatology $10,111-127(1990)$

E. N. Lorenz, The Essence of Chaos, University of Washington Press, Seattle, WA (1993)

D. P. Rowell, C. K. Folland, K. Maskell and M. Neil Ward, "Variability of Summer Rainfall over Tropical North Africa (1906-92): Observations and Modelling," Quarterly Journal of the Royal Meteorological Society 121, 669-704 (1995)

D. P. Rowell, Using an Ensemble of Multi-Decadal GCM Simulations to assess Potential Seasonal Predictability, Hadley Centre Technical Note No. CRTN 69, Bracknell, United Kingdom (1996)

M. J. Suarez, A. Arakawa and D. A. Randall, "Parameterization of the Planetary Boundary Layer in the UCLA General Circulation Model," Monthly Weather Review 96, 735-741 (1983)

M. F. Wehner and C. Covey, Description and Validation of the LLNL/UCLA Parallel Atmospheric GCM, LLNL Report No. UCRL-ID-123223, Livermore, CA (1995) 
P. Xie and P. A. Arkin, "Analyses of Global Monthly Precipitation Using Gauge Observations, Satellite Estimates, and Numerical Model Predictions," Journal of Climate 9, 840-858 (1996)

F. W. Zwiers, “Interannual Variability and Predictability in an Ensemble of AMIP Climate Simulations Conducted with the CCC GCM2," Climate Dynamics, submitted (1997.) 


\section{Figure Captions}

Figure 1: Annual mean precipitation [mm per day] as simulated by our model (top) and as estimated from observations compiled by Legates and Willmott (middle) and $\mathrm{X}$ ind Arkin (bottom). For the model result we show the average over all ensemble members.

Figure 2: Interannual standard deviation of 1979-1988 annual mean precipitation [mm per day] as estimated from observations compiled by $X_{i}$ and Arkin (top) and as simulated by our model (bottom). For the model result we show the average over all ensemble members.

Figure 3: 1983 minus 1988 annual mean precipitation [mm per day] as estimated from observations compiled by $\mathrm{Xi}$ and Arkin (top) and as simulated by our model (bottom). For the model result we show the average over all ensemble members.

Figure 4: Fraction of the variance of 1979-1988 annual mean precipitation that is attributable to changing SST and sea ice boundary conditions, calculated from all 20 ensemble members (top) and from a subset of 10 (bottom). 


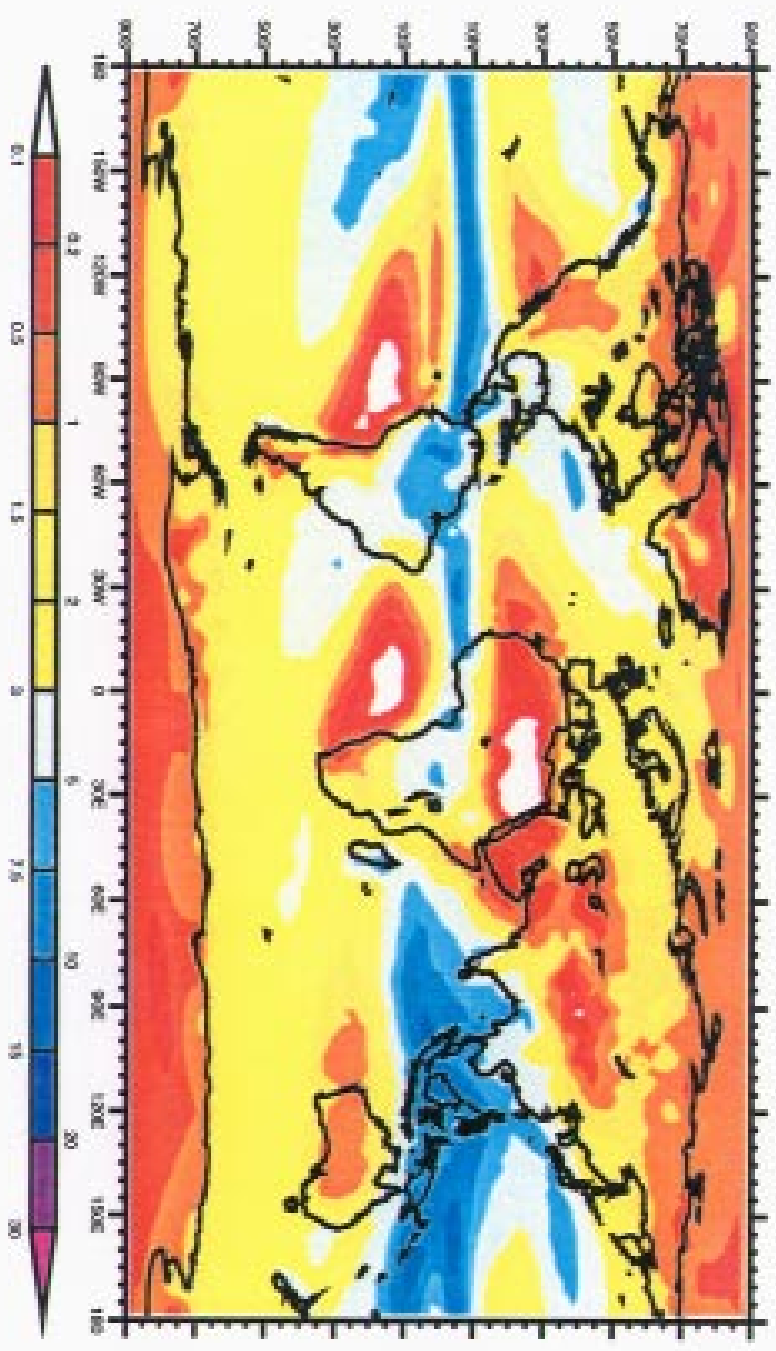

NCEP Obs

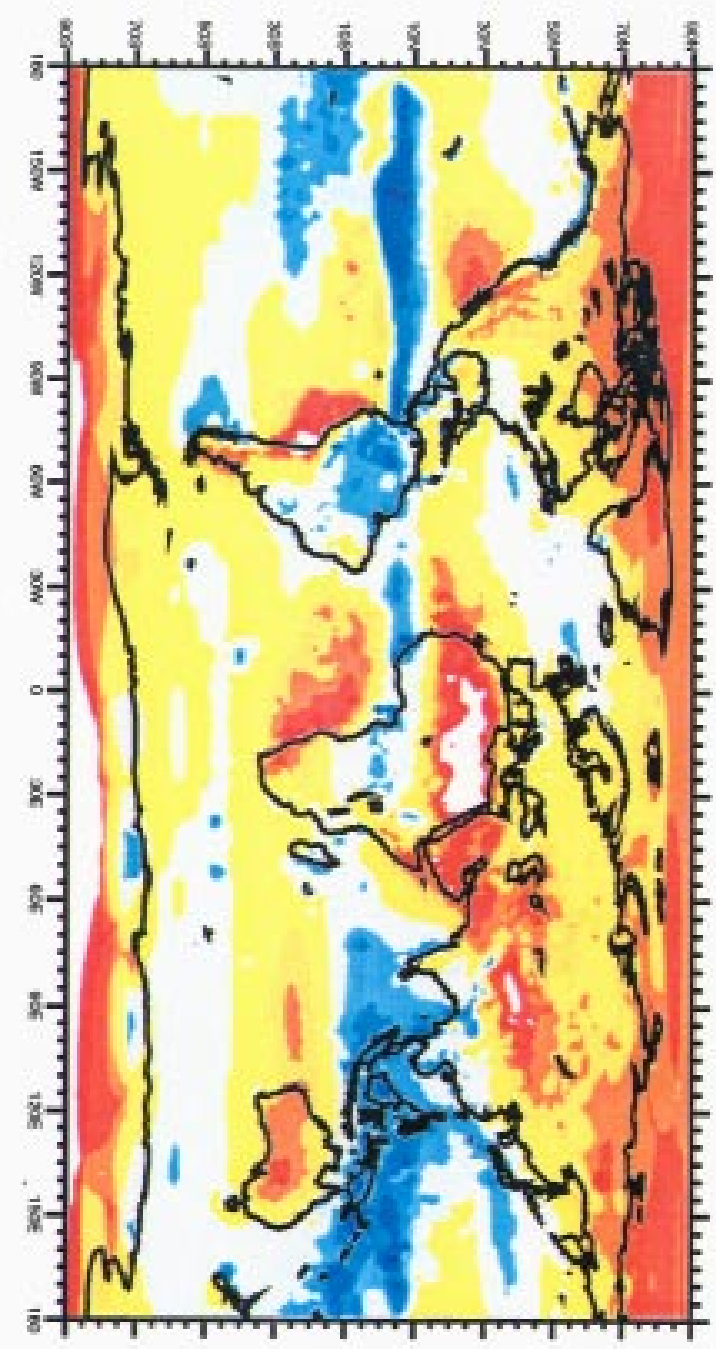

Legates-Willmott Obs

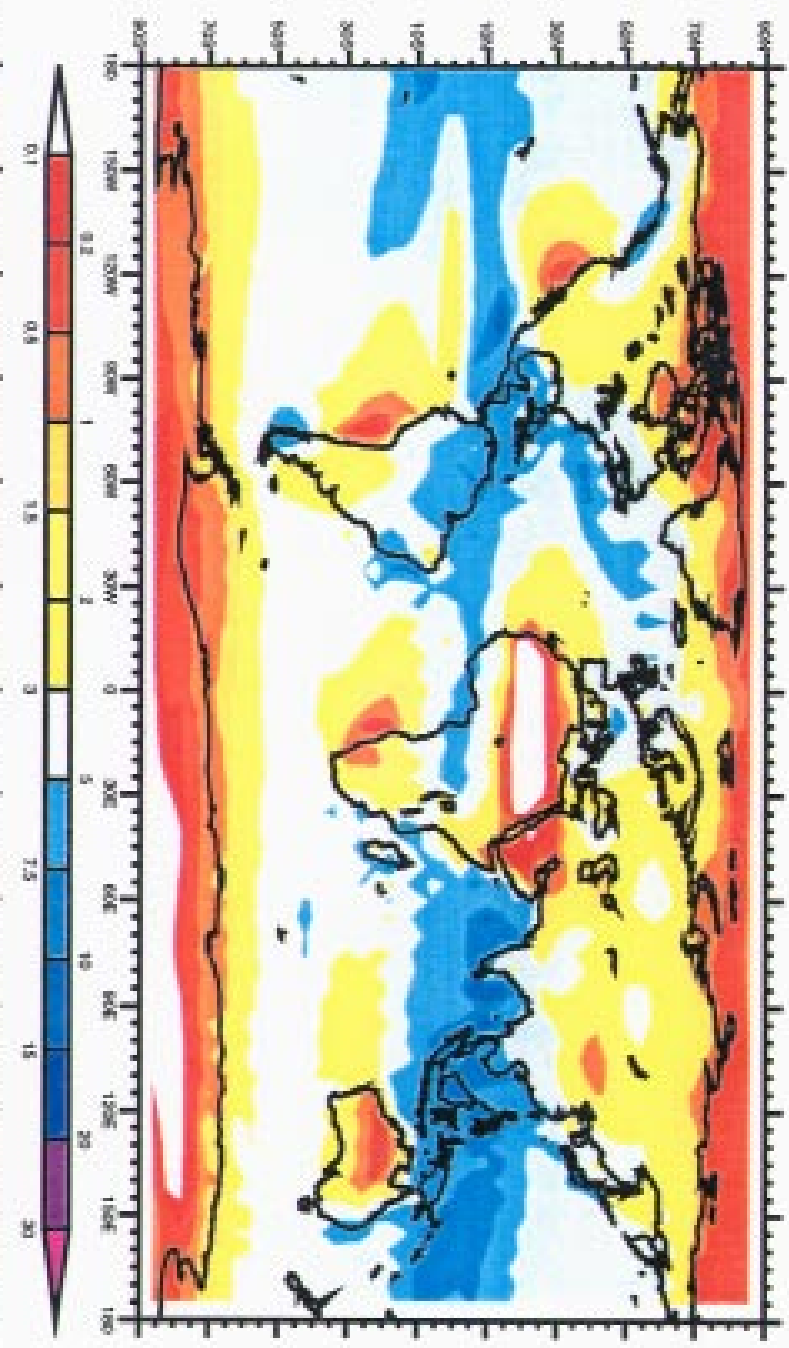

LLNL/UCLA Model 

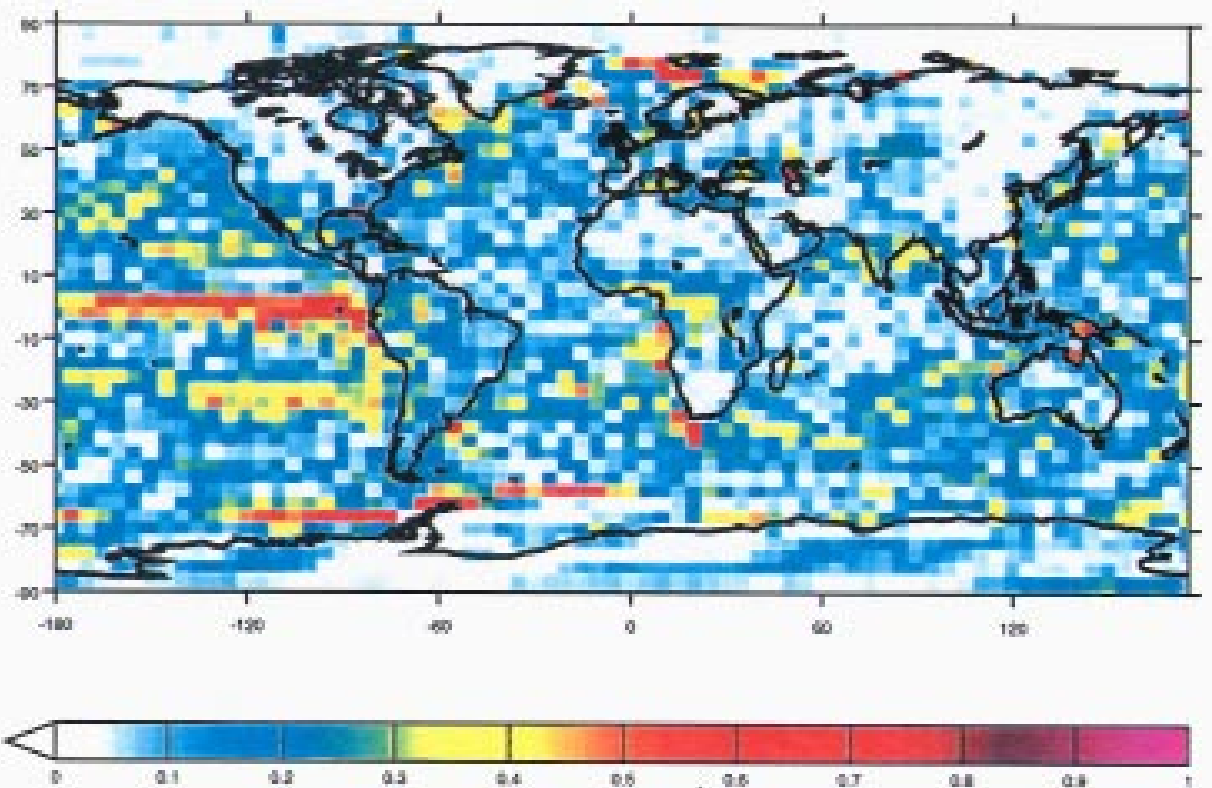

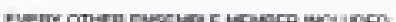
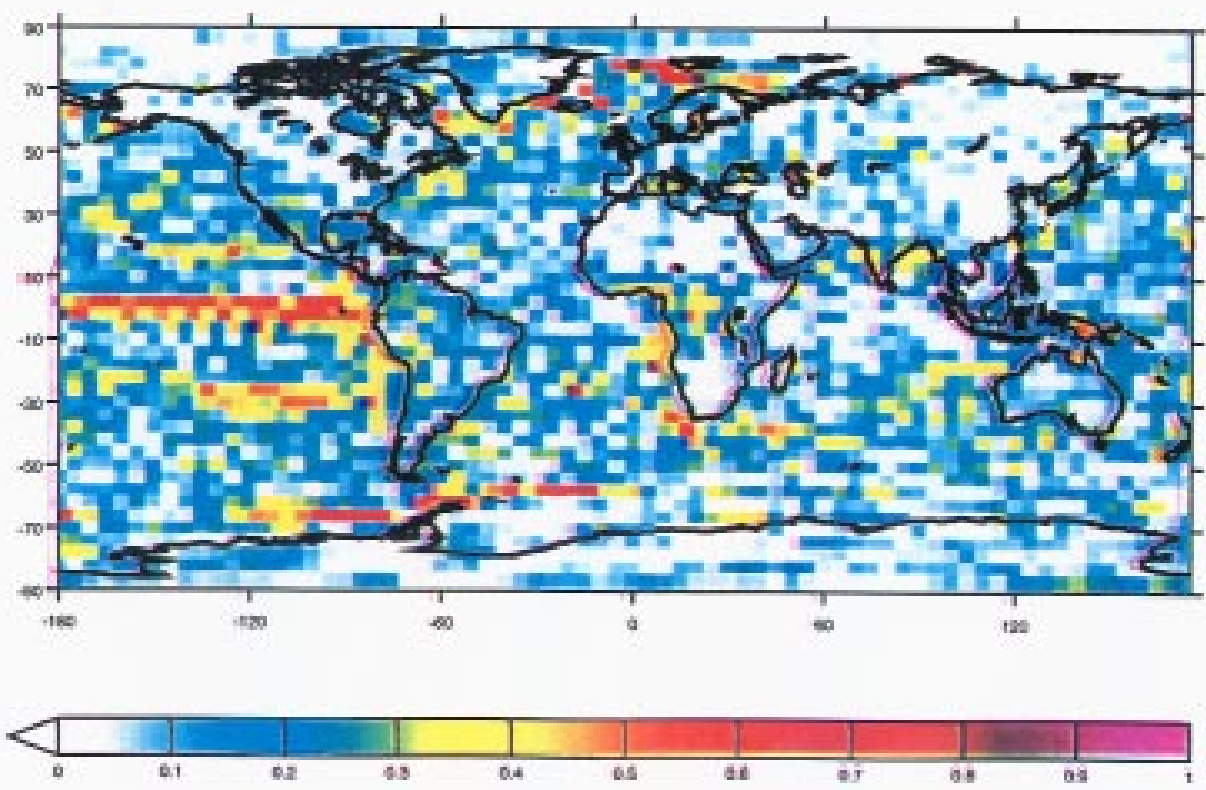


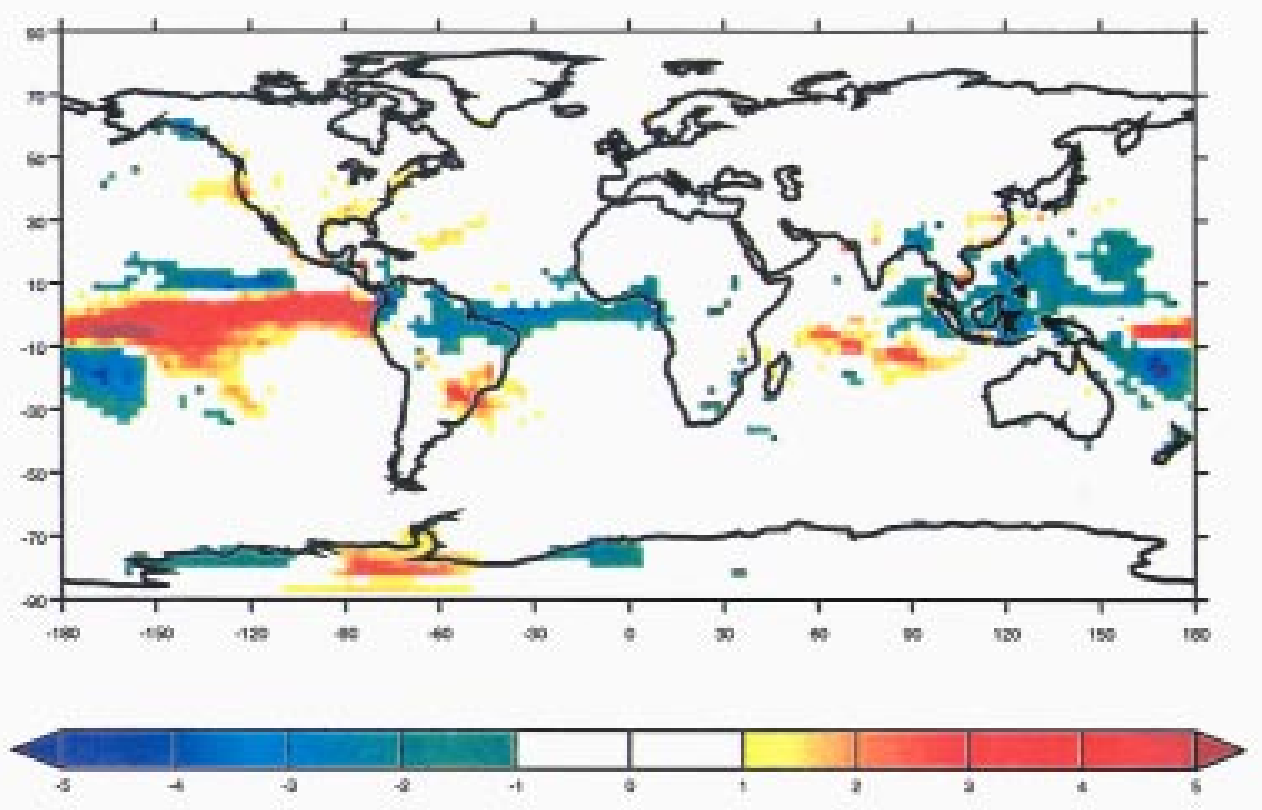

mocoel.
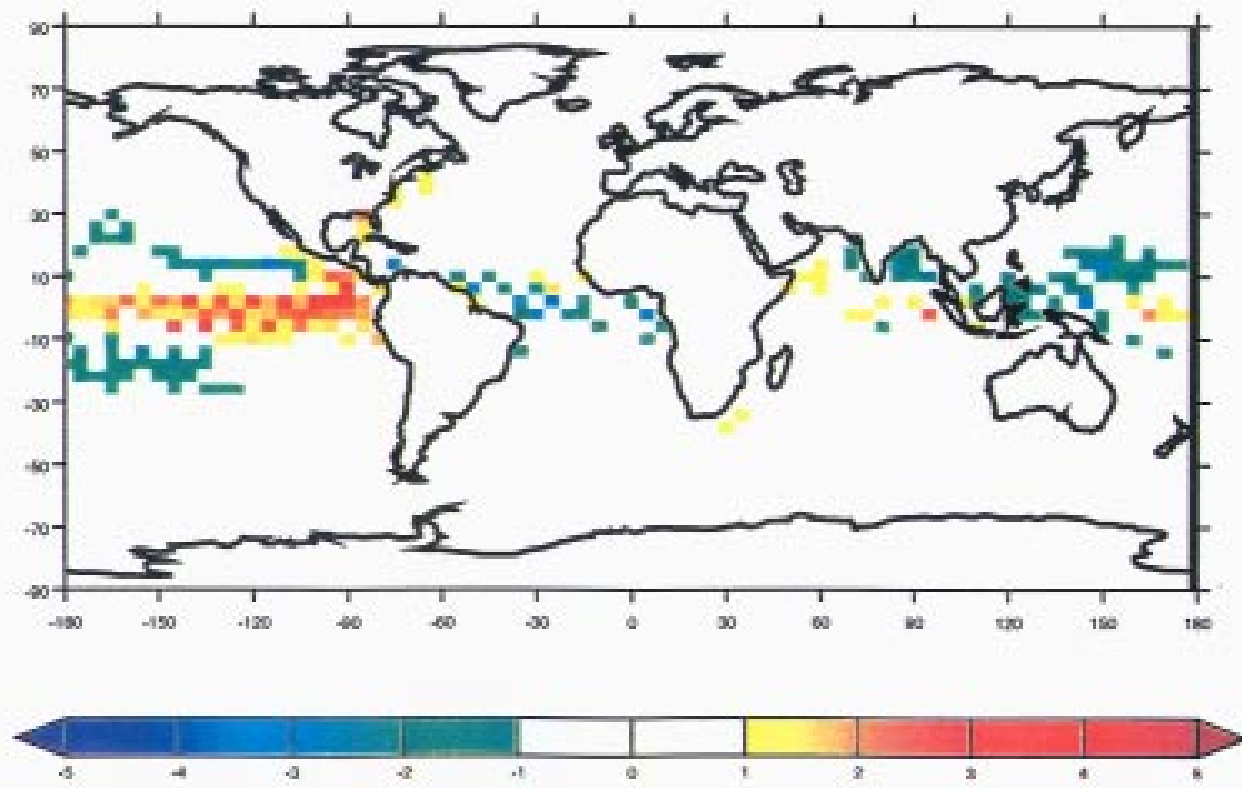

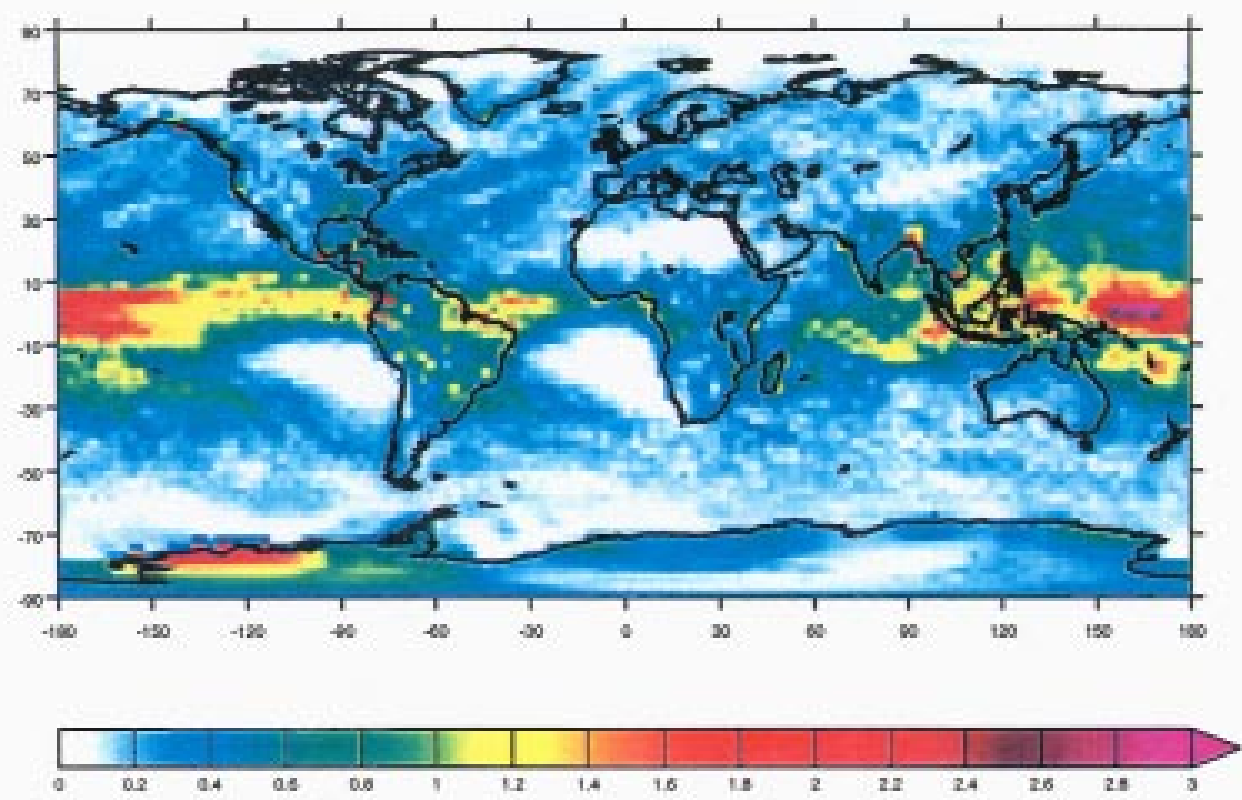

yoos
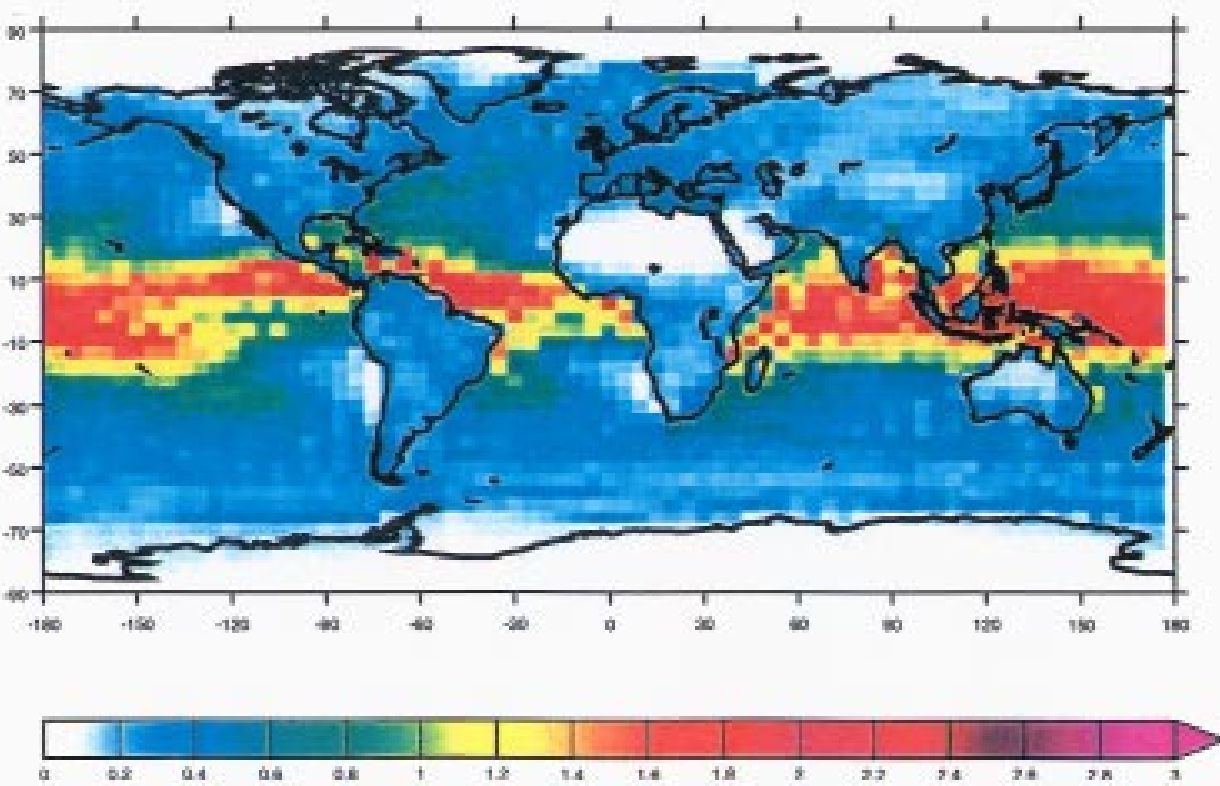


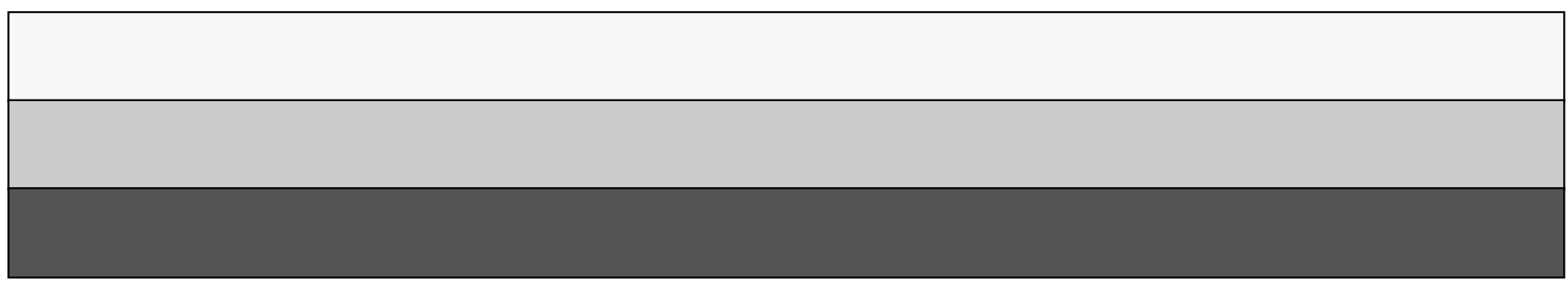

